ДУДИНА Ольга Мухаметшевна - кандидат философских наук, доцент департамента социологии, истории и философии Финансового университета при Правительстве РФ (125993, Россия, г. Москва, Ленинградский пр-кт, 49; OMDudina@fa.ru,dudinaom@yandex.ru)

\title{
МЕТОДЫ И КРИТЕРИИ ОЦЕНКИ ЭФФЕКТИВНОГО РУКОВОДИТЕЛЯ
}

\begin{abstract}
Аннотация. В статье описываются психологические и непсихологические критерии и методы оценки деятельности руководителя. Цель работы - раскрыть важность методов и методик оценки деятельности руководителя. Приоритетная задача - проанализировать достоинства и недостатки используемых методов оценки. Кроме теоретического анализа, был представлен эмпирический опыт диагностики эффективности деятельности руководителя на основе измерения неудовлетворенности работников деловыми и личностными качествами руководителя, влияющими на деятельность коллектива, в сочетании с социометрической и тестовой процедурами. Опыт показывает, что диагностика может быть использована для принятия управленческих решений. Автор приходит к выводу, что оценка руководителей, ориентированная на результат, приносит положительный эффект в коллективах.

Ключевые слова: оценка эффективности деятельности руководителя, метод оценки эффективности руководителя, технология SMART, методика оценки деловых и личностных качеств руководителя, измерение распространенности и глубины неудовлетворенности работников деловыми и личностными качествами руководителя
\end{abstract}

$\mathrm{O}$ дним из важнейших инструментов управления эффективностью предприятия является оценка эффективности деятельности его руководителей. Важными факторами успешного функционирования на предприятии системы оценки являются:

- четкая постановка цели проведения конкретной оценочной процедуры (например, среди отечественных организаций распространена такая ошибка: работникам объявляют, что мероприятие по оценке проводится с целью определения потребности в их обучении, а по итогам оценки увольняют часть сотрудников как не соответствующих должности, в результате это приводит к негативному отношению работников к оценке);

- выбор адекватного метода оценки (например, встречается такая ошибка: при принятии решения о продвижении руководителя среднего звена на должность руководителя предприятия используют метод оценки эффективности деятельности, который хорошо демонстрирует, насколько успешен сотрудник в нынешней должности, но не прогнозирует, как он справится с руководством всем предприятием).

Оценка эффективности деятельности (performance appraisal) является составной частью процедуры управления эффективностью деятельности предприятия (performance management). Она представляет собой измерение успешности работы руководителя с точки зрения достижения поставленных перед ним целей.

Оценка эффективности деятельности руководителей - это один из путей диагностики успешности функционирования процессов на предприятии и начало их корректировки в случае выявления отклонений от заданных параметров. Данный эффект достигается за счет предоставления руководителям обратной связи, предоставляющей им информацию о сильных и слабых сторонах их производственной деятельности, а также обсуждения путей ликвидации проблемных зон.

Метод оценки эффективности деятельности используют для 1) стимулирования руководителей к достижению поставленных целей; 2) определения целей 
и задач для руководителей на следующий период; 3) определения кандидатов на перемещения внутри предприятия; 4) принятия решений о материальном вознаграждении руководителей (например, премирование по итогам года) и моральном поощрении (например, определение «руководителя года»); 5) проведения конкурса среди руководителей на финансирование предприятием обучения.

Данный метод оценки рассчитан на руководителей первого уровня - тех, которые имеют в подчинении только рядовых сотрудников, но не руководителей (например, менеджеров, начальников отделов и т.д.). Она также может использоваться и для руководителей второго уровня - руководителей среднего звена, т.е. тех, в подчинении у которых находятся руководители первого уровня (например, руководитель филиала, заместитель директора по розничной сети и т.д.). Успешность деятельности руководителей как первого, так и второго уровня оценивается по достижениям коллектива (структурного подразделения), который они возглавляют.

Метод оценки эффективности руководителей подходит и для функциональных руководителей (например, заместитель директора по экономике и финансам, заместитель директора по персоналу и т.д.). В данном случае успешность деятельности руководителей будет оцениваться по результативности процесса, которым управляет руководитель (например, деятельность заместителя директора по персоналу можно оценивать по таким показателям, как удельный вес издержек на персонал в себестоимости продукции; процент укомплектованности штата, процент текучести и т.д.).

Чтобы судить, насколько эффективен тот или иной руководитель, нужны какие-то критерии, позволяющие такую оценку произвести. Выбор их отнюдь не так прост.

В первую очередь критерии можно разделить на психологические и непсихологические (результативность коллектива) (см. рис. 1).

Что касается психологии управления, то, во-первых, имеется многолетняя практика опенки руководителей на основе сравнения портрета «идеального» руководителя и каждого конкретного человека, либо работающего руководителем, либо состоящего в резерве на замещение. Это сопоставление проводят либо отобранные по специальным правилам эксперты, либо весь коллектив. Они выставляют конкретному руководителю баллы по каждому качеству и создают таким образом его деловой портрет.

У этого метода есть достоинства: качества оцениваемых работников хотя бы приблизительно измеряются при помощи одной и той же «линейки». Но есть у этого метода и недостатки: дело в том, что эффективность руководителя зависит не только от того, насколько у него выражены качества «идеального» руководителя, но и от того, насколько они сочетаются с деловыми качествами его подчиненных, насколько для данного конкретного коллектива подходят предлагаемые им стиль и методы управления.

Во-вторых, применяются методы тестирования. С их помощью выявляются основные качества и способности, необходимые для управленческой деятельности: интеллектуальные, коммуникативные, способность к лидерству и т.д. Здесь используются различные классические психологические тесты. Вместе с тем делаются попытки разработать новые тесты. В частности, известен метод тестирования, основанный на измерении общей способности к управленческой деятельности.

B-третьих, применяется метод анкетирования, позволяющий оценить, как, по мнению коллектива, справляется с выполнением своих функций конкретный руководитель. 

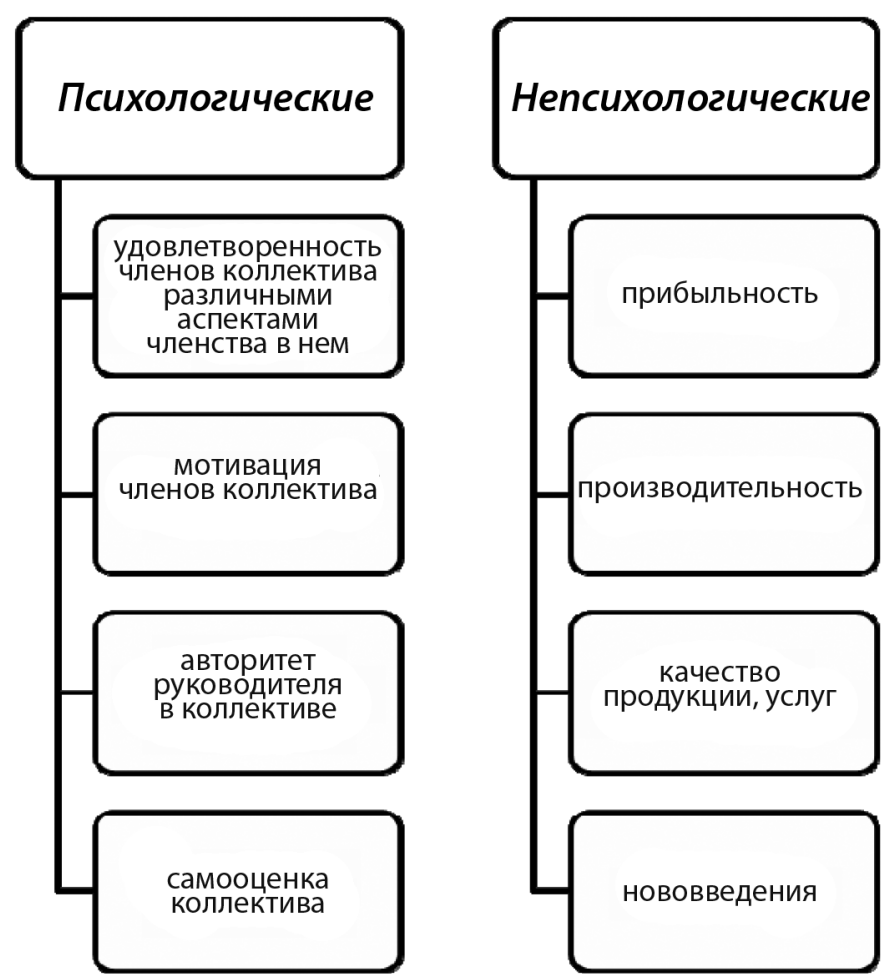

Рисунок 1. Психологические и непсихологические критерии оценки эффективности руководства

В-четвертых, используются социометрические методики, позволяющие выявить положение руководителя в структуре межличностных отношений коллектива.

Критерии эффективности руководителя также связаны с производственными и экономическими показателями, характеризующими такие критерии, как качество, объем, сроки получения производимых продуктов (оказываемых услуг). Наиболее универсальным критерием оценки работы руководителей является показатель чистой прибыли, причем чем выше позиция, которую занимает руководитель в организационной структуре, тем больший удельный вес имеет этот показатель в критериях оценки. Однако при использовании этого показателя в качестве основного критерия оценки необходимо учитывать ряд других показателей (например, таких, как использование основных и оборотных средств, эффективность капиталовложений, экономия прямых и косвенных затрат в издержках производства и обращения, текучесть персонала и т.д.). Анализ других показателей необходим по следующей причине: несмотря на высокий показатель прибыли за определенный период времени, могут существовать серьезные проблемы в управлении, которые повлияют на результативность подразделения в перспективе (например, такие, как сильный износ основных фондов, текучесть персонала, снижение издержек за счет снижения качества продукции и т.д.). Руководитель может не вкладывать средства в капитальный ремонт, техническое перевооружение, экономить на заработной плате сотрудников и т.Д., руководствуясь соображениями сиюминутной выгоды и не думая о стратегических планах предприятия. 
Критерии эффективности руководителя также оценивают по результатам внедрения и использования новых технологий и оборудования, темпам освоения новой продукции.

Кроме производственных и экономических показателей, можно также оценивать руководителей по достижению поставленных СМАРТ-задач (например, открыть 10 розничных магазинов, внедрить новую систему оплаты труда, поставить на предприятии управленческий учет и т.д.). В этом случае должны быть описаны качественные критерии, при которых задача будет считаться выполненной.

Цели и задачи должны быть поставлены с учетом известной технологии $S M A R T$, где $S$ (specific) - конкретность; $M$ (measurable) - измеримость; $A$ (achievable) достижимость; $R$ (relevant) - уместность; $T$ (timebound) - временные границы.

Метод оценки эффективности деятельности имеет ряд неоспоримых преимуществ. Он способствует объединению целей организации и целей ее руководителей, что ведет к развитию как самого предприятия, так и его руководителей. Но это происходит только в том случае, если поставленные цели обоснованно высокие и достижимые. При соблюдении этих условий у управленцев появляется вкус к победе, что стимулирует их к новым и новым свершениям. Хорошо поставленные цели и оценка результатов деятельности - это один из эффективных инструментов мотивации менеджеров, т.к. людям нравятся сложные, но выполнимые задачи, а также то, что их достижения оценивают и отмечают.

Легко достижимые цели также не способствуют прогрессу предприятия, т.к. слишком простая победа не приносит удовлетворения и не побуждает к достижениям.

Если руководители верят, что оценка эффективности деятельности способствует их карьере и увеличению благосостояния, то на предприятии формируется культура результативности.

Для успешного применения оценки эффективности деятельности необходимо, чтобы на предприятии был внедрен метод управления по целям (management by objectives). Впервые термин «управление по целям» был введен классиком менеджмента Питером Друкером почти 50 лет назад [Туленков 2011: 4]. Управление по целям - это единый стандарт управления подразделениями и отдельными сотрудниками для всего предприятия, где деятельность оценивается не по процессу, а по результату - достижению поставленных целей. Сначала определяются цели для всего предприятия, затем из них выводятся цели структурных подразделений, а исходя из целей структурных подразделений выставляют цели сотрудникам. Цели предприятия, структурных подразделений и сотрудников должны быть сбалансированы между собой.

Рассмотрим пример методики оценки эффективности руководителя, который был успешно использован в компании ОАО «Роснефть-ЦКБАСУнефтепродукТ». Для измерения отношения работников ЦКБ АСУнефтепродукт к различным сторонам деятельности и поведению руководителей отделов была использована методика оценки деловых и личностных качеств руководителя. Далее приводятся основные понятия указанной методики.

1. Состояние неудовлетворенности членов коллектива - такое эмоциональное состояние индивидов, которое характеризуется преобладанием отрицательных эмоциональных переживаний у членов коллектива при оценке ими условий жизнедеятельности своих коллективов. Естественно, что факторы, связанные с руководством, выступают для рядовых работников как условия их жизнедеятельности в трудовом коллективе. Практика исследований показала, что при решении конкретных управленческих задач данные, характеризующие неудовлетворенность членов коллектива условиями их жизнедеятельности, 
оказываются более информативными, чем данные, характеризующие их удовлетворенность.

2. Спектр неудовлетворенности - совокупность основных условий деятельности, вызывающих определенное состояние неудовлетворенности коллектива или группы его членов.

Уровень неудовлетворенности коллектива по компоненту $i$ определяется как частное от деления произведения масштаба и глубины неудовлетворенности на потенциально возможную неудовлетворенность коллектива по компоненту $i$ :

$$
h_{i}=\frac{m_{i} \cdot d_{i}}{p_{i}} ;
$$

где $h_{i}-$ уровень неудовлетворенности коллектива по компоненту $i$;

$m_{i}-$ масштаб неудовлетворенности коллектива по компоненту $i$;

$d_{i}$ - глубина неудовлетворенности коллектива по компоненту $i$ (глубина неудовлетворенности рассчитывается путем суммирования произведений долей лиц разной степени неудовлетворенности по компоненту $i$ на вес соответствующих степеней неудовлетворенности);

$p_{i}$ - потенциально возможная неудовлетворенность коллектива по компоненту $i$.

Уровень неудовлетворенности достаточно надежно свидетельствует о мере стремления коллектива к изменениям, связанным с тем или иным условием деятельности коллектива. При этом если уровень неудовлетворенности ниже 0,11 - коллектив будет стремиться не допустить никаких изменений в сфере соответствующих условий; равен $0,11-0,20$ - коллектив будет стремиться лишь к незначительным, чисто формальным изменениям в сфере соответствующих условий; составляет 0,21-0,40 - коллектив будет стремиться к заметным, содержательным изменениям в сфере соответствующих условий; равен 0,41-0,60коллектив будет стремиться к крупным, существенным изменениям в сфере соответствующих условий; выше 0,60 - коллектив будет стремиться к наиболее существенным, кардинальным изменениям в сфере соответствующих условий.

При анализе оценок руководителя коллектива также использовался ранжированный спектр неудовлетворенности коллектива, т.е. распределение компонентов спектра в порядке уменьшения уровня неудовлетворенности. Как правило, место определенного компонента в ранжированном спектре свидетельствует о степени значимости изменения соответствующего условия деятельности для работников коллектива и их успешной деятельности [Дудина 2009].

Как показали исследования, наибольшую значимость для работников представляют компоненты спектра, занимающие первые 10 мест в ранжированном спектре. Это должно определять и стратегию управленческих воздействий, которые должны быть в первую очередь направлены на устранение причин, вызывающих наиболее высокие уровни неудовлетворенности. Иная стратегия управленческих воздействий не дает сколько-нибудь существенного повышения эффективности деятельности трудовых коллективов.

Рассмотрим в качестве примера, как была апробирована описанная методика. Для апробирования методики в реальной ситуации были выбраны отделы А, Б, В ЦКБ АСУнефтепродукт. Помимо этой методики, проводилась также социометрическая процедура (с тщательным соблюдением конфиденциальности), в ходе которой задавался вопрос: «Кого бы Вы хотели видеть на месте руководителя Вашего отдела?» Она была направлена на изучение состоятельности действующего руководителя и наличия потенциальных кандидатур на место действующего руководителя. Если их много, то о состоятельности действующего руководителя говорить не приходится... Для более глубокого изучения 
личности руководителей было использовано тестирование по методу СМИЛ (стандартизированный многофакторный метод исследования личности, адаптированный к российской культуре доктором психологических наук профессором Л.Н. Собчик).

В отделе А из 13 чел. по списочному составу в опросе участвовали 11 чел., включая руководителя. По данным социометрической процедуры, он получил 4 выбора; 5 членов коллектива отказались от выбора, 2 выбора получил другой сотрудник.

В отделе Б из 13 чел. участвовали 8, не включая руководителя. По данным социометрической процедуры он получил 8 выборов.

В отделе В опрошены 16 чел., включая руководителя. Он получил 14 выборов. Кроме него были названы 3 сотрудника.

При подсчете уровня неудовлетворенности коллективов по вопросам, связанным с руководством, анкеты, заполненные руководителями, исключались. Ниже приводятся результаты подсчета по всем трем отделам (см. табл. 1).

Таблица 1

\section{Оценка работниками деловых качеств руководителей своих отделов}

\begin{tabular}{|l|c|c|c|}
\hline \multirow{2}{*}{ Компоненты спектра неудовлетворенности } & \multicolumn{3}{|c|}{ Руководство отделов } \\
\cline { 2 - 4 } & A & Б & В \\
\cline { 2 - 4 } & \multicolumn{2}{|c|}{ Уровень неудовлетворенности } \\
\hline 1. Деловые качества в целом & 0,07 & 0,04 & 0,09 \\
\hline 2. Инженерная деятельность руководителя & 0,14 & 0,00 & 0,07 \\
\hline 3. Инженерные способности руководителя & 0,30 & 0,08 & 0,10 \\
\hline 4. Организационная деятельность руководителя & 0,11 & 0,04 & 0,13 \\
\hline 5. Организационные способности руководителя & 0,05 & 0,08 & 0,10 \\
\hline 6. Организация труда в коллективе & 0,11 & 0,04 & 0,17 \\
\hline $\begin{array}{l}\text { 7. Отношение руководителя к инженерным } \\
\text { предложениям подчиненных }\end{array}$ & 0,12 & 0,07 & 0,10 \\
\hline $\begin{array}{l}\text { 8. Отношение к предложениям подчиненных в } \\
\text { сфере организации труда }\end{array}$ & 0,23 & 0,11 & 0,22 \\
\hline 9. Поведение руководителя на работе & 0,31 & 0,08 & 0,13 \\
\hline $\begin{array}{l}\text { 10. Отношение к критическим замечаниям } \\
\text { подчиненных }\end{array}$ & 0,38 & 0,03 & 0,16 \\
\hline $\begin{array}{l}\text { 11. Помощь в решении личных проблем } \\
\text { подчиненных }\end{array}$ & 0,20 & 0,00 & 0,13 \\
\hline 12. Взаимоотношения с подчиненными & 0,30 & 0,00 & 0,13 \\
\hline 13. Взаимоотношения в коллективе & 0,17 & 0,09 & 0,01 \\
\hline 14. Стиль и методы руководства & 0,22 & 0,09 & 0,08 \\
\hline 15. Авторитет руководства & 0,37 & 0,01 & 0,07 \\
\hline
\end{tabular}

Из данных таблицы можно сделать следующие заключения.

1. Работники всех трех отделов вполне удовлетворены деловыми качествами своих руководителей (как в целом, так и их проявлениями в инженерной и организационной деятельности); бесспорно признают инженерные и организационные способности своих руководителей; косвенным свидетельством 
удовлетворенности деловыми качествами руководителей является также очень низкий уровень неудовлетворенности по таким показателям, как организация труда и качество работы инженеров коллектива.

2. Сопоставление оценок работников трех отделов по качествам, связанным с умением руководителя использовать коллективный интеллектуальный потенциал (отношение к предложениям подчиненных в сфере инженерной деятельности и в сфере организации труда), свидетельствует о том, что руководителям отделов А и Б следует несколько более внимательно относиться к предложениям такого рода.

3. Сопоставление уровней неудовлетворенности работников всех трех отделов факторами, характеризующими отношение руководителей к критическим замечаниям подчиненных, помощь руководителей подчиненным в решении их личных нужд и проблем, взаимоотношения с подчиненными, стиль и методы руководства, свидетельствуют о том, что:

а) у работников отдела А эти факторы вызывают значительно более высокую неудовлетворенность, чем у работников отделов Б и В; работники отделов Б и В практически вполне удовлетворены этими аспектами руководства;

б) эти факторы вызывают значительно более высокую неудовлетворенность, чем деловые качества руководителя;

в) уровень неудовлетворенности работников отдела А факторами, характеризующими отношение руководителя к подчиненным, свидетельствует о стремлении работников к крупным, содержательным изменениям в этой области.

4. Аналогичным образом можно охарактеризовать восприятие работниками всех трех отделов норм поведения руководителей на работе: работники отдела А довольно заметно неудовлетворены нормами поведения руководителя на работе и стремятся к тому, чтобы руководитель отдела А внес крупные содержательные изменения в свое поведение (в сфере общения с подчиненными); в то же время работники отделов Б и В вполне удовлетворены этими факторами.

5. На основании пилотажного исследования можно сказать, что выбранная методика подходит к решению данной задачи, позволяет дифференцированно оценить различные деловые качества руководителей и сравнить совместимость руководителей и коллективов в данной организации.

Таким образом, практика показывает, что даже на тех предприятиях, которые не имеют четко сформулированных общих целей, оценка руководителей, ориентированная на результат, приносит положительный эффект, т.к. она способствует проведению дискуссий о целях, приоритетах и стратегиях, необходимых организации для успешного решения задач в долгосрочной перспективе.

Для успешного применения оценки эффективности деятельности также необходимо наличие формализованной системы планирования и отчетности, которая позволяет четко зафиксировать, а потом легко воспроизвести поставленные цели и задачи, а также достигнутые результаты.

\section{Список литературы}

Дудина О.М. 2009. Социально-психологический климат организации: возможности диагностики и коррекции. - Социокультурные факторы инновационного развития организации: материалы научно-практической интернет-конференции (с международным участием). М.: Изд-во МАИ. С. 191-195.

Туленков Н.В. 2011. Введение в теорию и практику менеджмента: учебное пособие. Киев: Изд-во МАУП. 308 с. 
DUDINA OI'ga Mukhametshevna, Cand.Sci. (Philos.), Associate Professor of the Department of Sociology, History and Philosophy, Financial University under the Government of the Russian Federation (49 Leningradsky Ave, Moscow, Russia, 125993;OMDudina@fa.ru,dudinaom@yandex.ru)

\title{
METHODS AND CRITERIA FOR EVALUATING AN EFFECTIVE MANAGER
}

\begin{abstract}
The article describes the psychological and non-psychological criteria and methods for assessing the activities of the leader. The purpose of the work is to reveal the importance of methods and techniques for assessing the activities of the manager. The priorities were to analyze the advantages and disadvantages of these evaluation methods. In addition to the theoretical analysis, the author presents the empirical experience of diagnosing the effectiveness of the manager's activity based on measuring the prevalence and depth of dissatisfaction of employees with the business and personal qualities of the manager, which affect the activities of the team in combination with the sociometric and test procedures. The experience shows that diagnostics can be used to make management decisions. The author concludes that the assessment of managers, focused on the result, brings a positive effect in the teams.

Keywords: evaluation of effectiveness of manager, method of assessing effectiveness of manager, SMART technology, diagnostics of business and personal qualities of manager, measurement of prevalence and depth of dissatisfaction of employees with business and personal qualities of manager
\end{abstract}

ПОРТНОВ Алексей Александрович - соискатель Тамбовского государственного технического университета (392000, Россия, г. Тамбов, ул. Советская, 106; AlexeyPortnov2010@таil.ru)

НЕФЁДОВ Дмитрий Вячеславович - подполковник полиции, начальник курса строевого подразделения Центра профессиональной подготовки ГУМВД России по Саратовской области (410062, Россия, г. Саратов, Московское ш., спецгородок ВСО)

\section{СПЕЦИФИКА ФУНКЦИОНИРОВАНИЯ ПРАВОРАДИКАЛЬНЫХ ОРГАНИЗАЦИЙ В РОССИИ И СТРАНАХ ЗАРУБЕЖНОЙ ЕВРОПЫ}

\begin{abstract}
Аннотация. Статья посвящена актуальным проблемам деятельности отечественных и зарубежных ультраправых партий и движений. Авторы статьи провели сопоставление тенденций развития национальных праворадикальных организаций. Основной акцент в работе делается на выявление первопричины популярности и успешной деятельности многих ультраправых организаций; формулируются рекомендации по пресечению экстремистской деятельности.
\end{abstract}

Ключевые слова: экстремизм, ксенофобия, ультраправые, национальная дифференциация, этническая преступность, скинхед-группировки, гастарбайтеры

$\mathrm{B}$ странах Западной и Восточной Европы в течение последних десятилетий, взяв курс на трансформацию и так называемый ребрендинг политического имиджа, крайне правые организации стремятся к всесторонней легитимации своей политической деятельности. Пройдя путь от полумаргинальных группировок, вызывающих недоверие и опасение у большинства законопослушных граждан, до респектабельных европейских партий - полноправных участников политического процесса в своих странах, они принимают активное участие в деятельности Европарламента и других международных организаций ${ }^{1}$.

\footnotetext{
${ }^{1}$ Крайне правые партии сформировали также несколько международных организаций: «Евронат» (Euronat), Альянс европейских национальных движений (Alliance of European National Movements) и принимают активное участие в деятельности националистического Альянса наций Европы.
} 